\title{
Kajian Pengaruh Waktu dan pH Optimum dalam Adsorpsi Methyl Violet dan Methylene Blue Menggunakan Abu Daun Bambu
}

\author{
Kuntari, Naela Salsa Bila, dan Meidi Yuwono \\ Jurusan Kimia, FMIPA \\ Universitas Islam Indonesia \\ bilanailasalsa@gmail.com
}

\begin{abstract}
Abstrak
Telah dilakukan adsorpsi methyl violet dan methylene blue menggunakan abu daun bambu. Penelitian ini bertujuan untuk melakukan karakterisasi adsorben dengan spektrofotometri FT-IR dan adsorpsi dengan parameter yang dipelajari adalah waktu interaksi dan $\mathrm{pH}$. Konsentrasi zat warna ditentukan dengan metode spektrofotometri UV-vis. Spektra FT-IR yang dihasilkan menunjukkan bahwa adsorben memiliki serapan karakteristik yang berasal dari gugus $\mathrm{Si}-\mathrm{O}$ dan $\mathrm{Al}-\mathrm{O}$. Hasil adsorpsi menunjukkan bahwa adsorpsi methyl violet optimum pada waktu kontak 12 menit dan $\mathrm{pH} 11$ dengan kapasitas adsorpsi sebesar 22,8738 mg/g dan adsorpsi methylene blue optimum pada waktu kontak 8 menit dan $\mathrm{pH} 11$ dengan kapasitas adsorpsi sebesar $17,9989 \mathrm{mg} / \mathrm{g}$.
\end{abstract}

Kata-kata kunci:abu daun bambu, methyl violet, methylen blue, adsorpsi

\begin{abstract}
Adsorption of methyl violet and methylene blue has been done on using bamboo leaf ash. This research aims to study the characterization adsorbent by FT-IR spectrophotometry and adsorption with the parameters interaction time and $\mathrm{pH}$. The concentration of the dye was determined quantitively by UV-Vis spectrophotometer. FT-IR spectogram of bamboo leaf ash show that typical fingerprint in IR spectrogram of af asdeobent with $\mathrm{Si}-\mathrm{O}$ and $\mathrm{Al}-\mathrm{O}$ groups. The adsorption results showed that optimum methyl violet adsorption at 12 minutes and $\mathrm{pH} 11$ with adsorption capacity of $22.8738 \mathrm{mg} / \mathrm{g}$ and adsorption of optimum methylene blue at contact time of 8 minutes and $\mathrm{pH} 11$ with adsorption capacity of $17.9989 \mathrm{mg} / \mathrm{g}$.
\end{abstract}

Keywords: bamboo leaf ash, methyl violet, methylen blue, adsorptionmethod

\section{PENDAHULUAN}

Pencemaran lingkungan merupakan salah satu masalah utama dalam kehidupan modern. Salah satu bentuk pencemaran lingkungan yang ada di sekitar kita adalah pencemaran akibat penggunaan zat pewarna yang bersifat anionik, kationik maupun non-ionik, seperti zat warna methyl violet dan methylene blue. Methyl violet merupakan salah satu zat warna yang digunakan untuk pewarnaan tekstil yang tergolong dalam zat warna karbon-nitrogen yang terdapat pada gugus benzena. Gugus benzena sangat sulit didegradasi, kalaupun dapat didegradasi membutuhkan waktu yang lama (Cristina, dkk., 2007). Zat warna Methylene blue merupakan salah satu zat warna dasar penting yang banyak digunakan dalam industry tekstil untuk pewarna kapas dan sutra (Muthuraman, dkk., 2009). Pengolahan limbah yang mengandung zat warna perlu dilakukan, karena jika tidak maka dapat menyebabkan pencemaran lingkungan.
Beberapa tahun terakhir metode pengolahan secara fisika, kimia dan perawatan biologis telah banyak digunakan untuk penghapusan pewarna dari larutan air atau limbah air seperti, koagulasiflokulasi (Tan, dkk., 2000), proses fenton (Behnajady, dkk., 2007), dan degradasi elektrokimia (Fan, dkk., 2008). Proses adsorpsi menggunakan karbon aktif adalah salah satu teknik yang paling efektif dan digunakan secara luas pada berbagai jenis bahan pewarna (Crini, 2006). Namun, penggunaan karbon aktif sangat terbatas karena tingginya biaya yang diperlukan. Oleh karena itu, banyak alternatif murah dengan adsorben dari bahan yang tersedia seperti biosorben dan bahan limbah dari industri dan pertanian.

Dalam penelitian ini adsorben yang diusulkan adalah abu daun bambu untuk mengurangi konsentrasi zat warna methylene blue dan methyl violet. Ketersediaan bahan baku yang melimpah dan 
kadar silika yang tinggi diharapkan abu daun bambu mampu mengadsorpsi zat warna methyl violet dan methylene blue. Penentuan abosrbansi dari zat warna methylene blue dan methyl violet menggunakan spektrofotometri UV-Visibel serta abu daun bambu dikarakterisasi dengan FT-IR.

\section{METODE}

\section{Preparasi dan karakterisasi adsorben abu daun bamboo}

Daun bambu kering dipotong kecil-kecil dan dioven selama 1 hari dengan suhu $105^{\circ} \mathrm{C}$, kemudian di furnace selama 2 jam dengan suhu $700^{\circ} \mathrm{C}$. Hasil kemudian dikarakterisasi menggunakan FTIR untuk mengetahui adanya silika ( $\mathrm{Si})$.

\section{Pengaruh waktu kontak pada methyl violet dan methylene blue}

Dua puluh miligram abu daun bambu dimasukkan ke dalam larutan methyl violet $20 \mathrm{mg} / \mathrm{L}$ dengan variasi waktu $2 ; 4 ; 6 ; 12$; dan 15 menit menggunakan shaker kecepatan pengadukan 200 rpm. Absorbansi diukur menggunakan spektrofotometer UV-visibel pada panjang gelombang maksimum. Waktu kontak optimum ditunjukkan dengan nilai persentase adsorpsi tertinggi. Dan 3,5 mg abu daun bambu dimasukkan ke dalam larutan methylene blue $10 \mathrm{mg} / \mathrm{L}$ dengan variasi waktu $4 ; 5 ; 6 ; 7 ; 8 ; 9$ dan 10 menit menggunakan shaker kecepatan pengadukan 200 rpm. Absorbansi diukur menggunakan spektrofotometer UV-visibel pada panjang gelombang maksimum. Waktu kontak optimum ditunjukkan dengan nilai persentase adsorpsi tertinggi.

\section{Pengaruh pH pada methyl violet dan methylene blue}

Dua puluh miligram mg abu daun bambu dimasukkan ke dalam larutan methyl violet $20 \mathrm{mg} / \mathrm{L}$ dengan variasi $\mathrm{pH} \mathrm{5;7;9}$ dan 11 dengan waktu optimum yang didapatkan menggunakan shaker kecepatan pengadukan $200 \mathrm{rpm}$. Absorbansi diukur menggunakan spektrofotometer UV-visibel pada panjang gelombang maksimum. Kondisi $\mathrm{pH}$ optimum ditunjukkan dengan nilai persentase adsorpsi tertinggi. Dan $5 \mathrm{mg}$ abu daun bambu dimasukkan ke dalam larutan methylene blue 10 $\mathrm{mg} / \mathrm{L}$ dengan variasi $\mathrm{pH} \mathrm{3;} \mathrm{5;} \mathrm{7;} 9$ dan 11 dengan waktu optimum yang didapatkan menggunakan shaker kecepatan pengadukan $200 \mathrm{rpm}$. Absorbansi diukur menggunakan spektrofotometer UV-visibel pada panjang gelombang maksimum. Kondisi $\mathrm{pH}$ optimum ditunjukkan dengan nilai persentase adsorpsi tertinggi.

\section{HASIL DAN PEMBAHASAN}

Silika yang diperoleh dari abu daun bambu yang dianilisis dengan FTIR dan spekrumnya diperlihatkan pada Gambar 1.Spektrum menunjukan beberapa puncak yang menunjukan adanya beberapa gugus fungsi dalam sampel, baik yang dimiliki oleh silika atau gugus fungsi dari zat lain dan pengotor yang tidak dapat dibersihkan seluruhnya. Puncak utama yang diyakini berkaitan dengan gugus fungsi silika adalah pada bilangan gelombang 3452,17 cm1. Puncak ini merupakan puncak yang khas untuk vibrasi ulur gugus - $\mathrm{OH}$ (gugus hidroksil) yang diyakini bahwa, dalam sampel terdapat gugus hidroksil ikatan $\mathrm{Si}-\mathrm{OH}$ atausilanol (Lin, dkk.,2001). Puncak kedua yang diyakini menunjukan gugus fungsi adalah puncak pada bilangan gelombang $1100,54 \mathrm{~cm}-1$, yang menunjukan adanya gugus fungsi Si-O-Si (Daifullah, dkk., 2003). Adanya gugus fungsi $\mathrm{Si}-\mathrm{O}-\mathrm{Si}$ diperkuat dengan adanya puncak pada bilangan gelombang $466,51 \mathrm{~cm}-1$, yang menunjukan ikatan Si-O (Lin, dkk., 2001), dan puncak pada $797,54 \mathrm{~cm}-1$ yang timbul akibat deformasi ikatan $\mathrm{Si}-\mathrm{O}$ pada $\mathrm{SiO} 4$.

Puncak lain dengan intensitas yang cukup signifikan terdapat pada daerah 1642,02 cm-1. Puncak ini menunjukan vibrasi regang $\mathrm{C}=\mathrm{O}$ dari hemiselulosa, yang kemungkinan ikut teradsorbsi oleh silika. Puncak lemah lainnya terdapat pada daerah $618,59 \mathrm{~cm}-1$, yang menunjukan adanya ikatan antara $\mathrm{Si}-\mathrm{O}$ dengan logam. Interpretasi data IR ini sesuai dengan analisis fungsional yang dilakukan oleh Kamath, dkk.,1998.

Karakterisasi adsorben dilakukan dengan analisis spektrofotometri FT-IR.daun bambu yang dianilisis dengan FT-IR. Hasil menunjukan puncak utama yang diyakini berkaitan dengan gugus fungsi silika adalah pada bilangan gelombang $3452,17 \mathrm{~cm}-1$. Puncak ini merupakan puncak yang khas untuk vibrasi ulur gugus $-\mathrm{OH}$ (gugus hidroksil) yang diyakini bahwa, dalam sampel terdapat gugus hidroksil ikatan $\mathrm{Si}-\mathrm{OH}$ atau silanol (Lin dkk., 2001). Puncak kedua yang diyakini menunjukan gugus fungsi adalah puncak pada bilangan gelombang 1100,54 cm-1, yang menunjukan adanya gugus fungsi $\mathrm{Si}-\mathrm{O}-\mathrm{Si}$ (Daifullah, dkk., 2003). Adanya gugus fungsi Si$\mathrm{O}-\mathrm{Si}$ diperkuat dengan adanya puncak pada bilangan gelombang 466,51 cm-1, yang menunjukan ikatan Si-O (Lin dkk, 2001), dan puncak pada $797,54 \mathrm{~cm}-1$ yang timbul akibat deformasi ikatan $\mathrm{Si}-\mathrm{O}$ pada $\mathrm{SiO} 4$. 
Puncak lain dengan intensitas yang cukup signifikan terdapat pada daerah 1642,02 cm-1. Puncak ini menunjukan vibrasi regang $\mathrm{C}=\mathrm{O}$ dari hemiselulosa, yang kemungkinan ikut teradsorbsi oleh silika. Puncak lemah lainnya terdapat pada daerah $618,59 \mathrm{~cm}-1$, yang menunjukan adanya ikatan antara $\mathrm{Si}-\mathrm{O}$ dengan logam. Interpretasi data IR ini sesuai dengan analisis fungsional yang dilakukan oleh Kamath \& Proctor (1998).

Penentuan kurva kalibrasi methyl violet dilakukan pada konsentrasi standar $0 ; 2 ; 3 ; 4 ; 5$; dan 6 pada panjang gelombang maksimum 585 $\mathrm{nm}$, diperoleh data absorbansi pada Tabel 1 .

Tabel 1 menunjukkan bahwa hubungan antara konsentrasi laratuan standar methyl violet dengan absorbansi berbanding lurus atau semakin besar konsentrasi larutan zat warna maka semakin besar pula hasil absorbansinya. Dari tabel 1 dapat dibuat grafik hubungan antara larutan standar methyl violet (sumbu $\mathrm{x}$ ) dan absorbansi (sumbu y) seperti Gambar 2.

Gambar 2 merupakan hubungan antara konsentrasi larutan standar zat warna methyl violet dengan absorbansi. Dari kurva kalibrasi tersebut diperoleh persamaan $\mathrm{y}=0,107 \mathrm{x}-0,005$ dan koefisien determinasi $\left(\mathrm{R}^{2}\right)$ sebesar 0,998. Dari koefisien determinasi yang diperoleh, dapat disimpulkan bahwa kurva kalibrasi yang diperoleh linier karena $>0,995$.

Penentuan kurva kalibrasi methylene blue dilakukan pada konsentrasi standar 0,$00 ; 1,20$; 2,$00 ; 2,80 ; 3,60 ;$ dan 4,40 pada panjang gelombang maksimum $663 \mathrm{~nm}$, diperoleh data absorbansi pada Tabel 2.

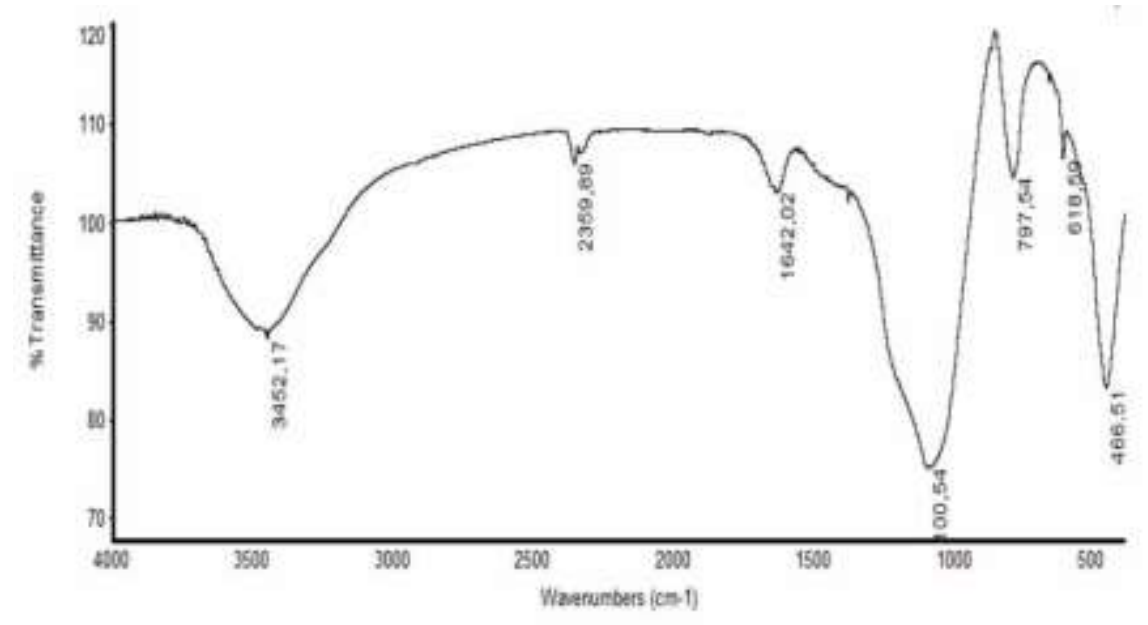

Gambar 1. Spektrum FT-IR Abu Daun Bambu

Hasil persentase adsorpsi methyl violet dan methylene blue parameter waktu kontak

Tabel 1. Hasil Absorbansi Larutan Strandar Methyl Violet

\begin{tabular}{cc}
\hline Konsentrasi (ppm) & Absorbansi \\
\hline 0 & 0 \\
\hline 2 & 0.214 \\
\hline 3 & 0.309 \\
\hline 4 & 0.410 \\
\hline 5 & 0.531 \\
\hline 6 & 0.649 \\
\hline
\end{tabular}

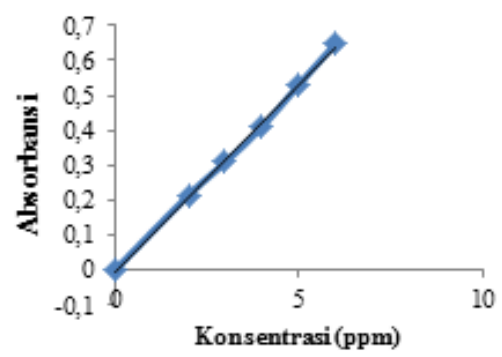

Gambar 2. Grafik hubungan antara larutan standar methyl violet dan absorbansi
Tabel 2. Hasil Absorbansi Larutan Strandar Methylene Blue

\begin{tabular}{cc}
\hline Konsentrasi (ppm) & Absorbansi \\
\hline 0.00 & 0.006 \\
\hline 1.20 & 0.218 \\
\hline 2.00 & 0.319 \\
\hline 2.80 & 0.489 \\
\hline 3.60 & 0.660 \\
\hline 4.40 & 0.770 \\
\hline
\end{tabular}

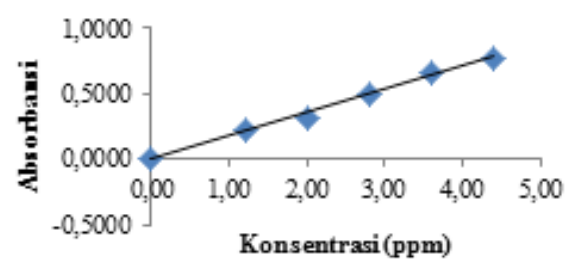

Gambar 3. Grafik hubungan antara larutan standar methylene blue dan absorbansi 
Tabel 2 menunjukkan bahwa hubungan antara konsentrasi laratuan standar methylene blue dengan absorbansi berbanding lurus atau semakin besar konsentrasi larutan zat warna maka semakin besar pula hasil absorbansinya. Dari tabel 2 dapat dibuat grafik hubungan antara larutan standar methylene blue (sumbu x) dan absorbansi (sumbu y) seperti Gambar 3.

Gambar 3 merupakan hubungan antara konsentrasi larutan standar zat warna methyl blue dengan absorbansi. Dari kurva kalibrasi tersebut diperoleh persamaan $\mathrm{y}=0.1769 \mathrm{x}-0.0025$ dan koefisien determinasi $\left(\mathrm{R}^{2}\right)$ sebesar 0,9954. Dari koefisien determinasi yang diperoleh, dapat disimpulkan bahwa kurva kalibrasi yang diperoleh linier karena > 0,995.

\section{Methyl violet}

Waktu kontak yang digunakan pada penelitian adalah $2,4,6,12$, dan 15 menit pada material abu daun sebanyak $20 \mathrm{mg}$. larutan methyl violet ini dianalisis menggunakan spektrofotometer UV-Vis single beam dengan panjang gelombang maksimum $585 \mathrm{~nm}$ dan diperoleh hasil pembacaan seperti pada Tabel 3 .

Hasil penelitian menunjukan bahwa waktu dimana adsorben abu daun bambu dalam mengadsorpsi methyl violet secara optimal berada pada waktu 12 menit dengan persentase adsorpsi sebesar $77.928 \%$. Hasil menunjukan bahwa persentase adsorpsi tertinggi pada waktu kontak 12 menit, hal ini dikarenakan kontak antara adsorben abu daun bambu dengan adsorbat semakin lama

Tabel 3. Persen Adsorpsi dan Kapasitas Adsorpsi Methyl violet

\begin{tabular}{lllll}
\hline $\begin{array}{l}\text { Waktu } \\
\text { Kontak } \\
\text { (menit) }\end{array}$ & Absorbansi & $\begin{array}{l}\text { Konsentrasi } \\
\text { Akhir }\end{array}$ & $\begin{array}{l}\text { \% } \\
\text { Adsorpsi }\end{array}$ & q(mg/g) \\
\hline 2 & 0.697 & 6.558 & 67.212 & 16.803 \\
\hline 4 & 0.594 & 5.595 & 72.025 & 18.006 \\
\hline 6 & 0.552 & 5.202 & 73.988 & 18.497 \\
\hline 12 & 0.467 & 4.414 & 77.928 & 19.482 \\
\hline 15 & 0.564 & 5.318 & 73.411 & 18.352 \\
\hline
\end{tabular}

Tabel 6. Persen Adsorpsi dan Kapasitas Adsorpsi Methylene Blue

\begin{tabular}{ccccc}
\hline $\mathbf{p H}$ & Absorbansi & $\begin{array}{c}\text { Konsentrasi } \\
\text { Akhir }\end{array}$ & $\begin{array}{c}\text { \% } \\
\text { Adsorpsi }\end{array}$ & $\mathbf{Q}$ \\
\hline 3 & 0.728 & 4.129 & 58.717 & 11.747 \\
\hline 5 & 0.758 & 4.299 & 57.022 & 11.408 \\
\hline 7 & 0.285 & 1.625 & 83.752 & 16.755 \\
\hline 9 & 0.251 & 1.433 & 85.674 & 17.139 \\
\hline 11 & 0.175 & 1.003 & 89.969 & 17.999 \\
\hline
\end{tabular}

sehingga zat warna yang terserap oleh abu daun bambu juga semakin banyak. Namun, pada waktu 15 menit kapasitas adsorpsi mengalami penurunan karena kapasitas adsorpsi optimum terjadi pada waktu 12 menit sehingga pada waktu diatas 9 menit, sehingga kapasitas adsorpsi mengalami penurunan.

Pengaruh $\mathrm{pH}$ pada absorpsi larutan methyl violet yang digunakan untuk pengujian memiliki konsentrasi $20 \mathrm{ppm}$ dalam volume $25 \mathrm{~mL}$. variasi $\mathrm{pH}$ yang digunakan adalah $\mathrm{pH} 5,7,9$, dan 11 yang dikontakkan dengan material abu daun sebanyak $20 \mathrm{mg}$. larutan methyl violet ini dianalisis menggunakan spektrofotometer UV-Vis single beam dengan panjang gelombang maksimum 585 $\mathrm{nm}$, dengan waktu kontak 8 menit dan diperoleh hasil pembacaan seperti pada Tabel 4.

Hasilnya menunjukan bahwa proses adsorpsi dipengaruhi oleh kondisi $\mathrm{pH}$ dimana pada kondisi $\mathrm{pH}$ basa zat warna yang teradsorpsi menggunakan abu daun bambu semakin besar. Nilai absorbansi methyl violet terbaik ditunjukan pada saat $\mathrm{pH} 11$ dengan nilai persentase adsorpsi $91.495 \%$.

\section{Methylene blue}

Waktu kontak yang digunakan pada penelitian adalah 4,5,6,7,8,9 dan 10 menit pada material abu daun sebanyak 3,5 mg. larutan methylene blue ini dianalisis menggunakan spektrofotometer UV-Vis single beam dengan panjang gelombang maksimum $663 \mathrm{~nm}$ dan diperoleh hasil pembacaan seperti pada Tabel 5.

Tabel 4. Persen Adsorpsi dan Kapasitas Adsorpsi Methyl violet

\begin{tabular}{ccccc}
\hline pH & Absorbansi & $\begin{array}{c}\text { Konsentrasi } \\
\text { Akhir }\end{array}$ & \% Adsorpsi & q \\
\hline 5 & 0.739 & 6.956 & 65.218 & 16.304 \\
\hline 7 & 0.642 & 6.047 & 69.766 & 17.442 \\
\hline 9 & 0.774 & 7.277 & 63.614 & 15.903 \\
\hline 11 & 0.177 & 1.701 & 91.495 & 22.874 \\
\hline
\end{tabular}

Tabel 5. Persen Adsorpsi dan Kapasitas Adsorpsi Methylene Blue

\begin{tabular}{ccccc}
\hline $\begin{array}{c}\text { Waktu } \\
\text { Kontak } \\
\text { (menit) }\end{array}$ & Absorbansi & $\begin{array}{c}\text { Konsentrasi } \\
\text { Akhir }\end{array}$ & $\begin{array}{c}\% \\
\text { Adsorpsi }\end{array}$ & q(mg/g) \\
\hline 4 & 0.276 & 1.574 & 84.261 & 24.073 \\
\hline 5 & 0.269 & 1.535 & 84.657 & 24.186 \\
\hline 6 & 0.253 & 1.444 & 85.561 & 24.444 \\
\hline 7 & 0.238 & 1.359 & 86.409 & 24.687 \\
\hline 8 & 0.206 & 1.179 & 88.217 & 25.204 \\
\hline 9 & 0.226 & 1.292 & 87.087 & 24.881 \\
\hline 10 & 0.231 & 1.319 & 86.804 & 24.800 \\
\hline
\end{tabular}




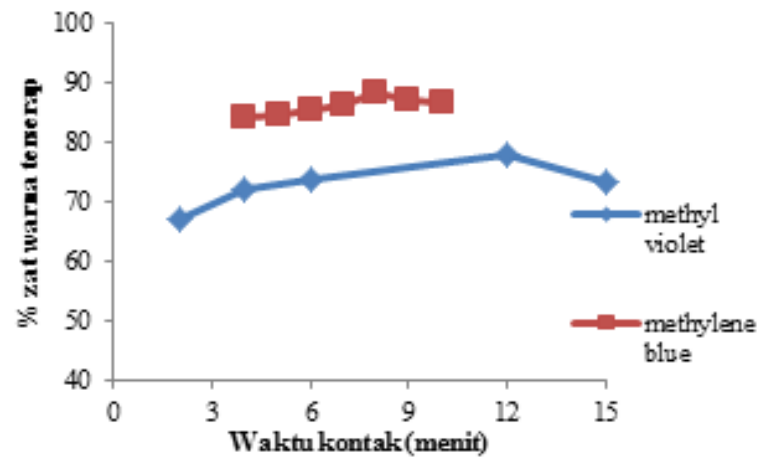

Gambar 4. Hubungan antara Waktu Kontak dengan \% Zat Warna Terserap

Hasil penelitian menunjukan bahwa waktu dimana adsorben abu daun bambu dalam mengadsorpsi methylene blue secara optimal berada pada waktu 8 menit dengan persentase adsorpsi sebesar 88,217\%. Hasil menunjukan bahwa persentase adsorpsi tertinggi pada waktu kontak 8 menit, hal ini dikarenakan kontak antara adsorben abu daun bambu dengan adsorbat semakin lama sehingga zat warna yang terserap oleh abu daun bambu juga semakin banyak. Namun, pada waktu 9 sampai 10 menit kapasitas adsorpsi mengalami penurunan karena kapasitas adsorpsi optimum terjadi pada waktu 8 menit sehingga pada waktu diatas 9 menit, kapasitas adsorpsi mengalami penurunan.

Pengaruh $\mathrm{pH}$ pada absorpsi larutan methylene blue yang digunakan untuk pengujian memiliki konsentrasi $10 \mathrm{ppm}$ dalam volume $10 \mathrm{~mL}$. variasi $\mathrm{pH}$ yang digunakan adalah $\mathrm{pH} 3,5,7,9$, dan 11 yang dikontakkan dengan material abu daun sebanyak $5 \mathrm{mg}$. larutan methylene blue ini dianalisis menggunakan spektrofotometer UV-Vis single beam dengan panjang gelombang maksimum $663 \mathrm{~nm}$, dengan waktu kontak 8 menit dan diperoleh hasil pembacaan seperti pada Tabel 6.

Hasilnya menunjukan bahwa proses adsorpsi dipengaruhi oleh kondisi $\mathrm{pH}$ dimana pada kondisi $\mathrm{pH}$ basa zat warna yang teradsorpsi menggunakan abu daun bambu semakin besar. Nilai absorbansi methylene blue terbaik ditunjukan pada saat $\mathrm{pH} 11$ dengan nilai persentase adsorpsi 89,969\%.

Gambar 1 menunjukan bahwa waktu optimum adsorpsi methyl violet terjadi pada waktu 12 menit

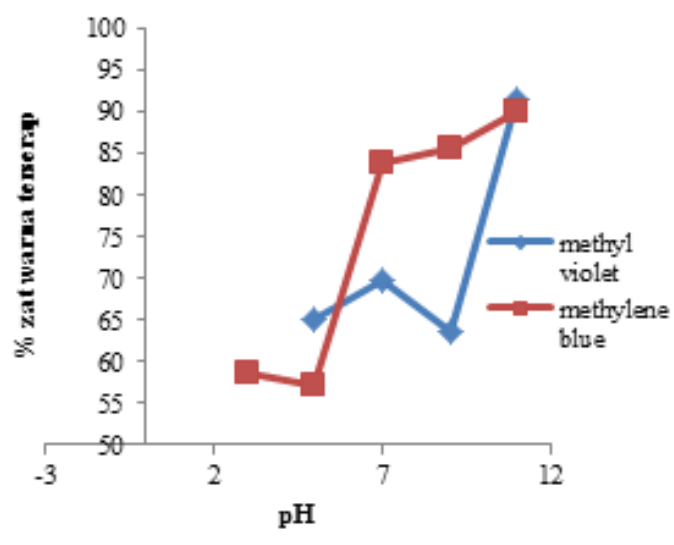

Gambar 5. Hubungan antara $\mathrm{pH}$ dengan \% Zat Warna Terserap

dengan persentase adsorpsi sebesar 77,93\%. disi kesetimbangan sehingga bertambahnya waktu kontak tidak menambah persentase adsorpsi. Sementara adsorpsi methylene blue optimal terjadi pada waktu kontak 8 menit dengan persentase adsorpsi sebesar 88,22\%. Penurunan persentase adsorpsi setelah waktu optimum dikarenakan telah mencapai kondisi kesetimbangan sehingga bertambahnya waktu kontak tidak menambah persentase adsorpsi.

Variasi $\mathrm{pH}$ pada adsorpsi larutan methyl violet yang digunakan untuk pengujian adalah $\mathrm{pH}$ 5, 7, 9, dan 11, sementara variasi $\mathrm{pH}$ pada adsorpsi larutan methylene blue adalah $\mathrm{pH} 3,5,7,9$, dan 11 . Gambar 2 menunjukan bahwa proses adsorpsi dipengaruhi oleh kondisi $\mathrm{pH}$ dimana pada kondisi $\mathrm{pH}$ basa zat warna yang teradsorpsi menggunakan abu daun bambu semakin besar. Nilai persentase adsorpsi methylene blue tertinggi ditunjukan pada saat $\mathrm{pH} 11$ yaitu dengan nilai 91,50\%. Nilai adsorpsi methylene blue tertinggi ditunjukan pada saat $\mathrm{pH} 11$ dengan nilai persentase adsorpsi $89,97 \%$.

\section{KESIMPULAN}

Karakterisasi abu daun bambu menggunakan FTIR menunjukan beberapa puncak yang membuktikan adanya beberapa gugus fungsi silika dalam sampel, yaitu pada bilangan gelombang $3452,17 \mathrm{~cm}^{-1}(\mathrm{Si}-$ $\mathrm{OH}), 1100,54 \mathrm{~cm}-1$ (Si-O-Si), 466,51 cm ${ }^{-1}(\mathrm{Si}-\mathrm{O})$. Hasil adsorpsi methylene blue optimum pada waktu kontak 8 menit dan $\mathrm{pH} 11$ dengan kapasitas adsorpsi $17,9989 \mathrm{mg} / \mathrm{g}$ dan methyl violet optimum pada waktu kontak 12 menit dan $\mathrm{pH} 11$ dengan kapasitas adsorpsi 22,8738 mg/g. 


\section{DAFTAR PUSTAKA}

Behnajady, M. A., Modirshahla, N., \& Ghanbary, F. 2007. A kinetic model for the decolorization of C.I. Acid Yellow 23 by Fenton process. Journal of Hazardous Materials, 148, 98-102.

Crini, G. 2006. Non-conventional low-cost adsorbents for dye removal: a review. Bioresource Technology, 97, 1061-1085.

Daifullah, A.A.M., Girgis, B.S. \& Gad, H.M.H. 2003.Utilization of Agro-Residues (Rice Husk) in Small Waste Water Treatment Plans. Material Letters, 57:1723-1731.

Fan, I., Zhou, Y., Yang, W., Chem, G., \& Yang, F. 2008.Electrochemical degradation of aqueous solution of Amaranth azo dye on ACF under potentiostatic model. Dyes and Pigments, 76, 440-446.

Kamath, S.R. and Proctor, A. 1998.Silica Gel from Rice Husk Ash: Preparation and Characterization. Cereal Chemistry, 75, 484-487.
Lin, J., Siddiqui, J.A. \& Ottenbrite, M. 2001.Surface Modification of Inorganic Oxide Particles with Silane Coupling Agent and Organic Dyes. Polymer Advance Technology, 12:285-292.

Maria Christina P., Mu'nisatun S., Rany Saptaaji dan Djoko Marjanto. 2007. Studi Pendahuluan Mengenai Degradasi Zat Warna Azo dalam Pelarut Air Menggunakan Mesin Berkas Elektron 340 keV/10 mA.JFN.Vol.1 No.1, ISSN 19788738.Hlm. 32.

Muthuraman, G., Teng, T. T., Leh, C. P., \& Ismail, N. 2009.Extraction and recovery of methylene blue from industrial wastewater using benzoic acid as an extractant. Journal of Hazardous Materials, 163, 363369.

Tan, B. H., Teng, T. T., \& Omar, A. K. M. 2000.Removal of dyes and industrial dye wastes by magnesium chloride. Water Research, 34, 597-601. 